ScIDoC

\section{Prevalence of Dental Malocclusion Among Children with Physical, Sensory and Neuropsychological Disabilities in Dar es Salaam, Tanzania}

Research Article

Vedasto Byarugaba V, Mtaya Mlangwa M, Mabula Machibya F*

Department of Orthodontics, Paedodontics and Community Dentistry, Muhimbili University of Health and Allied Sciences, Dar es salaam, Tanzania.

\title{
Abstract
}

Introduction: Proper occlusion is an important component of overall oral health of a child since malocclusion is associated with oral diseases like dental caries, periodontal diseases and temporal-mandibular disorders. Its impact on facial appearance may adversely affect social interactions and psychological well-being of the child. Children with disabilities overwhelmingly suffer from the impact of malocclusion more than the general population. Paying attention to this condition will lead to an improvement in quality of life of these children.

Material and Methods: A cross sectional survey was done among children with disabilities residing in Dar Es Salaam region, Tanzania. Data was collected using structured questionnaires for parents/teachers of the respective school children and clinical examination of malocclusion was done to children using the criteria described by WHO (1997).

Results: The study included 384 participants with majority of children being between 12 and 17 years of age: in addition, males composed $60.4 \%$ of the sample. Most of the children $(69 \%)$ had one or more type(s) of malocclusion/s: Children with neuropsychological disabilities were more affected with malocclusion $(75.9 \%)$ than other group of disabilities. Increased overjet $(18.8 \%)$ and reverse overjet $(6.2 \%)$ were both prevalent in neuropsychological disabilities than other groups. In addition, children with neuropsychological disabilities had higher prevalence of open and deep bite, $25 \%$ and $10.7 \%$, respectively.

Conclusion: Malocclusions were prevalent in a greater proportion of children with disabilities: In particular, those with neuropsychological disabilities had significantly higher prevalence of malocclusion, followed by those with physical and sensory disabilities.

\section{Introduction}

The World Health Organization (WHO) defines a handicapped individual as one who, over an appreciable time, is prevented by a physical or mental condition from full participation in the normal activities of his age group, including social, recreational, educational and vocational activities [1].

According to WHO, the term disability covers impairments, activity limitations and participation restrictions: In addition, impairment is further categorized into physical, cognitive, intellectual, mental, sensory, developmental, or combination of these conditions.

It is widely reported that individuals with disabilities have poorer oral health status compared to those in the general population [2-6]. Some previous studies have reported up to $95 \%$ or higher prevalence of malocclusion among children with disabilities [7, 8]. The reported prevalence of malocclusion in the general population ranges from 22 to 76 percent $[9,10]$. Age and social-cultural differences of the studied population as well as the variations in malocclusion classification and diagnostic criteria or indices used by researchers account for the big range of malocclusion reported worldwide $[11,12]$. In contrary, the type of disability is the main reason for disparities of reported malocclusion prevalence among handicapped people $[8,13-15]$.

*Corresponding Author:

Ferdinand Mabula Machibya,

Department of Orthodontics, Paedodontics and Community Dentistry, Muhimbili University of Health and Allied Sciences, P. O. Box 65014, Dar es salaam, Tanzania. Tel: $+255-222151135$

Fax: +255222150465

E-mail: frmachibya@yahoo.com

Received: January 02, 2017

Accepted: February 07, 2017

Published: February 27, 2017

Citation: Vedasto Byarugaba V, Mtaya Mlangwa M, Mabula Machibya F (2017) Prevalence of Dental Malocclusion Among Children with Physical, Sensory and Neuropsychological Disabilities in Dar es Salaam, Tanzania. Int J Dentistry Oral Sci. 4(2), 427-433. doi: http://dx.doi.org/10.19070/2377-8075-1700085

Copyright: Mabula Machibya $\mathbf{F}^{\circ}$ 2017. This is an open-access article distributed under the terms of the Creative Commons Attribution License, which permits unrestricted use, distribution and reproduction in any medium, provided the original author and source are credited. 
The neuropsychologically disabled patients suffer the most with malocclusion compared to other group of disabilities: Whereas, sensory and physically disabled patients are relatively less affected. Vittek et al., [13] and Viglid [8] reported more than 90\% prevalence of malocclusions among subjects with cerebral palsy and Down's syndrome, respectively. Nonetheless, the reported prevalence of malocclusion for sensory and physically disabled subjects ranges from 27 to 58 percent $[9,14]$.

The factors associated with high prevalence of malocclusion in communities with disabilities are diverse. They include genetic predisposition, increased risk to dental trauma, involuntary detrimental oral habits, limitations in maintaining good oral hygiene, barriers in accessing dental care, congenital and developmental orofacial defects as well as social-cultural context of specific communities $[2,4,16,17]$.

The muscles of the face and oral cavity play great role in facial growth and occlusal development by influencing the growth of the bone as a tissue affecting the vascular supply to the bone and as a force element in association with the amount of load applied on jaw bones during mastication [18-20]. Most patients with neuropsychological disability suffer from abnormal orofacial muscle tone and imbalance with improper lips and tongue posture [21]; these features increase the risk of developing malocclusion in these individuals.

Good oral health status of an individual is an important component for overall physical health, oral function, ability to communicate, physical appearance (dental aesthetics) and ultimate quality of life $[2,13]$. It is relatively difficult to maintain good oral health of individuals with disabilities because they may often have involuntary behavior that adversely affect their oral health. Some are unable to perform oral hygiene activities and face many limitations in accessing dental care $[2,3,17]$. The social-cultural differences also play a role in the variations of malocclusion prevalence observed between various communities. The same phenomenon applies on malocclusions in children with disabilities [8, 9, 22]. In many developed/western countries, malocclusions in these children is very common, with up to $90 \%$ of children displaying some form of malocclusions $[8,13]$. The conditions are also quite common in Asian countries, with a reported prevalence of $67 \%$ dental aberration among patients with Down's syndrome in Malaysia [23] and up to $70 \%$ in India [24]. Furthermore, in some parts of Africa it is as well common: A prevalence of $55.3 \%$ has been reported in Nigeria by Onyeaso et al., [25].

Although the epidemiology of malocclusion is extensively studied among disabled individuals worldwide, the reported occurrence of malocclusion for every specific type of disability is inconsistent. Moreover, in Tanzania to date, there is no published data regarding the prevalence of malocclusions in children with neuropsychological, sensory and physical disabilities. However, following influx of children with special needs such as children with those disabilities to the largest Dental clinic in the country (Muhimbili hospital), a higher prevalence was suspected among Tanzanian disabled children.

The main objective of the current study was to determine the prevalence of malocclusion in children with Neuropsychological, Sensory and Physical disabilities in Dar es Salaam, Tanzania.

\section{Materials and Methods}

A cross sectional survey of primary school children with neuropsychological, sensory and physical disabilities in Dar es Salaam, Tanzania was conducted in 2014.

\section{Study Population}

The study involved 384 children with neuropsychological (Mental retarded children, Down's syndrome, Autism and Attention Deficit Hyperactive Disorder), physical andsensory (Vision and Hearing) disabilities aged 6 to 17 years.

The sample consisted of primary school children with disabilities attending special schools for handicapped children. These schools were from all the three districts of Dar es Salaam region namely; Temeke, Ilala and Kinondoni.

The sample included pupils from 10 schools selected from a list of schools (sampling frame) obtained from all municipalities of Dar es Salaam. At the schools, all children who were present were included in the study.

Assuming a previous prevalence of $50 \%$ with 1.96 standard deviation and $5 \%$ marginal error, a sample size of 384 subjects was required for the study.

Children with physical disabilities, neuropsychological disabilities and sensory disabilities who were 6-17 years of age were included. The study excluded children with other disabilities apart from neuropsychological, sensory and physical and those with very severe disabilities such that clinical examination was very difficult to be performed at the school setting, as well as subjects with history of orthodontic treatment.

\section{Methods of Data Collection}

The study used both questionnaire and clinical examination in data collection. The structured questionnaires for parents/teachers of respective school children were filled first, followed by clinical examination to children. The examination of the children was conducted by one trained and calibrated examiner, the principal investigator (PI), using occlusal registration according to WHO criteria [26], with slight modifications.

\section{Validity and Reliability}

A pilot study was done to test the research instrument in terms of the time taken for the interview, double meanings, clarity and content of the instruments.

The examiner was trained and calibrated on how to score malocclusions. Intra-examiner consistencies varied from good to excellent, with Kappa values ranging from 0.894 to 1.000 .

\section{Data Processing and Statistical Analysis}

Data analysis was done using Statistical Package for Social Sciences (SPSS) version 20.0. The data was checked for any errors then frequency distributions were analysed and displayed to find the prevalence of malocclusions among children with physical, 
sensory and neuropsychological disabilities.

Bivariate associations were studied by Chi-Square statistics; these were used to find out if there was a statistically significant association between malocclusions and other variables/factors. P-value was set at 0.05 .

\section{Ethical Clearance and Informed Consent}

Ethical clearance was obtained from Muhimbili University of Health and Allied Sciences (MUHAS) and permission to work with children was sought from local administration authorities and schools administrations. Written informed consent was requested from the participants, parents and teachers before clinical examinations and interviews. Informed verbal consent was requested from the participants, parents and teachers before clinical examinations and interviews.

\section{Results}

The study included 384 participants with majority of the children being between 12 and 17 years of age. The detailed socio demographic distribution of participants is given in Table 1.
Regarding prevalence of malocclusion; overall findings showed that $265(69 \%)$ of children suffered from one or more types of malocclusion: Only $31 \%$ of them were free from dental malalignment. A small proportion of children (1\%) had up to seven different types of malocclusions recorded as shown in Figure 1.

Considering the distribution of participants by type of their disabilities children with sensory disabilities dominated the groups (45.1\%) followed by Neuropsychological (29.2\%) and Physical (25.8\%). Multiple types of disabilities co-existed in some cases.

The analysis of malocclusion distributions by children's specific type of disabilities revealed that children with neuropsychological disabilities had more increased overjet $(>5 \mathrm{~mm})$ and reverse overjet (18.8\% and $6.2 \%$ respectively), compared to children with other disabilities.

In the vertical occlusal plane; most of children with sensory and physical disabilities were free from vertical malocclusion, $80.9 \%$ and $72.7 \%$ respectively; and children with neuropsychological disabilities had higher prevalence of open (25\%) and deep (10.7\%) bite than children of other groups of disabilities.

Among the malocclusions assessed in the transverse plane; posterior cross-bite affected children with physical disabilities $(11.1 \%)$

Table 1. Socio Demographic Distribution of Children with Neuropsychological, Sensory and Physical Disabilities by Number and Percentage.

\begin{tabular}{|c|c|c|c|}
\hline Variable & Category & Number (n) & Percentage (\%) \\
\hline \multirow{4}{*}{ District } & Temeke & 218 & 56.8 \\
\cline { 2 - 4 } & Ilala & 121 & 31.5 \\
\cline { 2 - 4 } & Kinondoni & 45 & 11.7 \\
\hline \multirow{2}{*}{ Age } & $6-11$ years & 155 & 40.4 \\
\cline { 2 - 4 } & $12-17$ years & 229 & 59.6 \\
\hline \multirow{3}{*}{ Gender } & Male & 232 & 60.4 \\
\cline { 2 - 4 } & Female & 152 & 39.6 \\
\hline \multirow{3}{*}{ With whom do you live } & Parents & 190 & 49.5 \\
\cline { 2 - 4 } & Guardians & 25 & 6.5 \\
\cline { 2 - 4 } & Hostels & 169 & 44 \\
\hline
\end{tabular}

Figure 1. Distribution of Children with Physical, Neuropsychological and Sensory Disabilities by Number of Anomalies.

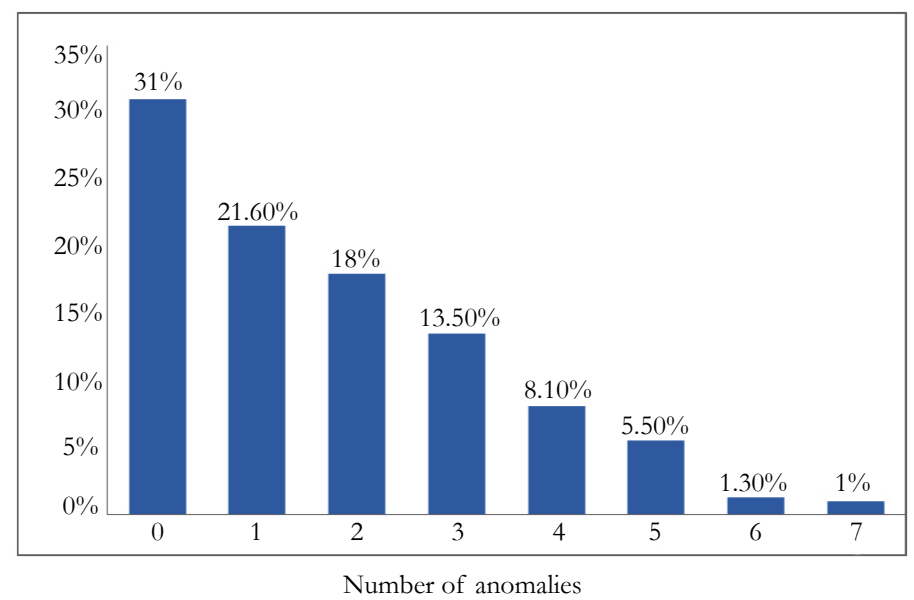


more than other groups of disabilities and children with neuropsychological disabilities had higher prevalence of scissors bite $(5.4 \%)$ than other groups of disabilities (Table 2$)$.

The results showed that crowding in the incisal segments was more prevalent $(28.6 \%)$ among children with neuropsychological disabilities than other groups of disabilities. Children with physical disabilities had more spacing $(14.1 \%)$ in the maxillary incisal segments than other groups of disabilities (Table 3). Overall, children with neuropsychological disabilities were most $(75.9 \%)$ affected by dental malocclusion compared to those with Sensory disabilities (65.9\%) and Physical disabilities (66.7\%).

In respect to participants' distribution by their occlusal status, majority of children with physical disabilities had Angle's Class I molar relationship $(87.9 \%)$ compared to neuropsychological $(75.9 \%)$ and sensory (73.6\%). More details are shown in Tables 4 and 5 .

\section{Discussion}

Good facial appearance enhances positive peer appraisal which strengthens an individual's self-esteem. Thus, malocclusion with impact on individual's facial appearance may adversely affect social interactions and psychological well-being $[27,28]$.

Children with disabilities suffer more from oral health problems than the general population $[2,29,30]$. The results of this study indicated that majority of children $(69 \%)$ had one or more type(s) of malocclusions.

While facial appearance is an important determinant of social acceptability and personality [31], with impact on how we choose people to hire or help, as well as partners for dating and socialization: Disabled individuals with compromised oral-facial health are further challenged by high prevalence of malocclusion in communities which tend to judge individuals by their physical appearance $[31,32]$. Malocclusion in children with disabilities possess an additional obstacle to social acceptance and compromises all aspects of oral functions and may have great bearing on children's quality of life. Several studies have addressed malocclusion epidemiology and treatment challenges of disabled children and recommended various measures to rescue the oral health of these children, with

Table 2. Prevalence and Number of Specific Types of Inter-Arch Malocclusions in a Sample of Children with Physical, Neuropsychological and Sensory Disabilities.

\begin{tabular}{|c|c|c|c|}
\hline \multicolumn{2}{|c|}{ Type of occlusion } & \multicolumn{2}{c|}{ Distribution } \\
\hline Occlusal Plane/Category & Occlusal Trait & Frequency (n) & Percentage (\%) \\
\hline \multirow{4}{*}{ Molar relation-Right side } & Class I & 301 & 78.4 \\
\cline { 2 - 4 } & Class II & 48 & 12.5 \\
\cline { 2 - 4 } & Class III & 35 & 9.1 \\
\hline \multirow{4}{*}{ Molar relation-Left side } & Class I & 303 & 78.9 \\
\cline { 2 - 4 } & Class II & 45 & 11.7 \\
\cline { 2 - 4 } & Class III & 36 & 9.4 \\
\hline \multirow{4}{*}{ Overjet } & No increased overjet $>5 \mathrm{~mm}$ & 346 & 90.1 \\
\cline { 2 - 4 } & Increased overjet $>5 \mathrm{mmm}$ & 38 & 9.9 \\
\cline { 2 - 4 } & Reversed overjet & 18 & 4.7 \\
\hline \multirow{3}{*}{ Vertical } & Normal & 281 & 73.2 \\
\cline { 2 - 4 } & Deep bite & 50 & 13.0 \\
\cline { 2 - 4 } & Edge to edge & 19 & 4.9 \\
\cline { 2 - 4 } & Open bite & 34 & 9.9 \\
\cline { 2 - 4 } & Cross-bite posterior & 22 & 5.7 \\
\cline { 2 - 4 } & Scissors bite & 16 & 4.2 \\
\hline \multirow{2}{*}{ Transverse } & & & \\
\hline
\end{tabular}

Table 3. Prevalence and Number of Specific Types of Intra-Arch Malocclusions in a Sample of Children with Physical, Neuropsychological and Sensory Disabilities.

\begin{tabular}{|c|c|c|c|}
\hline \multicolumn{2}{|c|}{ Type of Malocclusion } & Frequency (n) & Percentage (\%) \\
\hline \multirow{2}{*}{ Crowding incisal segment maxilla } & Yes & 89 & 23.2 \\
\cline { 2 - 4 } & No & 295 & 76.8 \\
\hline \multirow{2}{*}{ Crowding incisal segment mandibular } & Yes & 82 & 21.4 \\
\cline { 2 - 4 } & No & 302 & 78.6 \\
\hline \multirow{2}{*}{ Spacing incisal segment maxilla } & Yes & 46 & 12.0 \\
\cline { 2 - 4 } & No & 338 & 88.0 \\
\hline \multirow{2}{*}{ Spacing incisal segment mandibular } & Yes & 34 & 8.9 \\
\cline { 2 - 4 } & No & 350 & 91.1 \\
\hline
\end{tabular}


Table 4. Distribution of Children with Physical, Neuropsychological and Sensory Disabilities by their Occlusal Status.

\begin{tabular}{|c|c|c|c|c|c|c|c|c|}
\hline \multirow{2}{*}{\multicolumn{3}{|c|}{ Types of Occlusions }} & \multicolumn{6}{|c|}{ Types of Disabilities } \\
\hline & & & \multicolumn{2}{|c|}{ Physical } & \multicolumn{2}{|c|}{ Sensory } & \multicolumn{2}{|c|}{ Neuropsychological } \\
\hline \multirow{4}{*}{ Molar relation right side } & \multicolumn{2}{|c|}{ Occlusal trait } & $\mathbf{n}$ & $\%$ & $\mathrm{n}$ & $\%$ & $\mathbf{n}$ & $\%$ \\
\hline & \multicolumn{2}{|c|}{ Class I } & 87 & 87.9 & 131 & 73.6 & 85 & 75.9 \\
\hline & \multicolumn{2}{|c|}{ Class II } & 6 & 6.06 & 29 & 16.3 & 16 & 14.3 \\
\hline & \multicolumn{2}{|c|}{ Class III } & 6 & 6.06 & 18 & 10.1 & 11 & 9.8 \\
\hline \multirow{3}{*}{ Molar relation left side } & \multicolumn{2}{|c|}{ Class I } & 85 & 85.9 & 136 & 76.4 & 84 & 75 \\
\hline & \multicolumn{2}{|c|}{ Class II } & 8 & 8.1 & 22 & 12.4 & 17 & 15.2 \\
\hline & \multicolumn{2}{|c|}{ Class III } & 6 & 6 & 20 & 11.2 & 11 & 9.8 \\
\hline \multirow{2}{*}{$\begin{array}{l}\text { Increased overjet } \\
\quad>5 \mathrm{~mm}\end{array}$} & \multicolumn{2}{|l|}{ Yes } & 5 & 5.1 & 15 & 8.4 & 21 & 18.8 \\
\hline & \multicolumn{2}{|l|}{ No } & 94 & 94.9 & 163 & 91.6 & 91 & 81.2 \\
\hline \multirow{2}{*}{ Reversed overjet } & \multicolumn{2}{|l|}{ Yes } & 3 & 3 & 8 & 4.5 & 7 & 6.2 \\
\hline & \multicolumn{2}{|l|}{ No } & 96 & 97 & 170 & 95.5 & 105 & 93.8 \\
\hline \multirow{4}{*}{ Vertical relationship } & \multicolumn{2}{|l|}{ No } & 72 & 72.7 & 144 & 80.9 & 68 & 60.7 \\
\hline & \multicolumn{2}{|c|}{ Open bite } & 15 & 15.2 & 8 & 4.5 & 28 & 25 \\
\hline & \multicolumn{2}{|c|}{ Deep bite } & 9 & 9.1 & 14 & 7.9 & 9 & 10.7 \\
\hline & \multicolumn{2}{|c|}{ Edge to edge } & 3 & 3 & 12 & 6.7 & 4 & 3.6 \\
\hline \multirow{4}{*}{ Transverse relationship } & \multirow{2}{*}{$\begin{array}{l}\text { Posterior } \\
\text { cross-bite }\end{array}$} & Yes & 11 & 11.1 & 5 & 2.8 & 6 & 5.4 \\
\hline & & No & 88 & 88.9 & 173 & 97.2 & 106 & 94.6 \\
\hline & \multirow{2}{*}{ Scissors bite } & Yes & 4 & 4.0 & 6 & 3.4 & 6 & 5.4 \\
\hline & & No & 95 & 96.0 & 172 & 96.6 & 106 & 94.6 \\
\hline
\end{tabular}

$\mathrm{n}=$ number of children, $\%=$ percentage

Table 5. Distribution of Children with Physical, Neuropsychological and Sensory by their Intra-Arch Occlusal Status.

\begin{tabular}{|c|c|c|c|c|c|c|c|c|}
\hline \multirow{2}{*}{\multicolumn{3}{|c|}{ Type of malocclusions }} & \multicolumn{6}{|c|}{ Types of disabilities } \\
\hline & & & \multicolumn{2}{|c|}{ Physical } & \multicolumn{2}{|c|}{ Sensory } & \multicolumn{2}{|c|}{ Neuropsychologica } \\
\hline & & & $\mathrm{n}$ & $\%$ & $\mathbf{n}$ & $\%$ & $\mathrm{n}$ & $\%$ \\
\hline \multirow{12}{*}{ Intra arch } & \multirow{2}{*}{ Spacing incisal maxillary segment } & Present & 14 & 14.1 & 20 & 11.2 & 12 & 10.7 \\
\hline & & Absent & 85 & 85.9 & 158 & 88.8 & 100 & 89.3 \\
\hline & \multirow{2}{*}{ Spacing incisal mandibular segment } & Present & 10 & 10.1 & 14 & 7.9 & 10 & 8.9 \\
\hline & & Absent & 89 & 89.1 & 164 & 92.1 & 102 & 91.1 \\
\hline & \multirow{2}{*}{ Crowding incisal maxillary segment } & Present & 23 & 23.2 & 36 & 20.2 & 32 & 28.6 \\
\hline & & Absent & 76 & 76.8 & 142 & 79.8 & 80 & 71.4 \\
\hline & \multirow{2}{*}{ Crowding incisal segment mandibular } & Present & 23 & 23.2 & 33 & 24.1 & 27 & 24.1 \\
\hline & & Absent & 76 & 76.8 & 145 & 81.5 & 85 & 75.9 \\
\hline & \multirow{2}{*}{ Upper median diastema } & Present & 10 & 10.1 & 24 & 13.5 & 10 & 8.9 \\
\hline & & Absent & 89 & 89.9 & 154 & 86.5 & 102 & 91.1 \\
\hline & \multirow{2}{*}{ Lower median diastema } & Present & 2 & 2 & 2 & 1.1 & 4 & 2.1 \\
\hline & & Absent & 97 & 98 & 176 & 98.9 & 108 & 97.9 \\
\hline
\end{tabular}

$\mathrm{n}=$ number of children, $\%=$ percent

special health care need on the globe $[2-6,22]$.

The present research is the first in Tanzania that has considered the prevalence of malocclusions among children with neuropsychological, sensory and physical disabilities.

The $69 \%$ malocclusions prevalence is considerably higher than that which was reported in Nigeria by Onyeaso et al., [22]. This prevalence is much lower than that which was reported in India by Aggarwal et al., [33], who reported the prevalence of up to $84 \%$ in their population of children with disabilities.
Considering specific types of malocclusions among children with neuropsychological, sensory and physical disabilities, majority of children had Angle's class I molar relationship (78\%). This prevalence is lower than $87.4 \%$ which was reported in Nigeria by Utomi and Onyeaso [34] among children of the same disabilities. Likewise, lower prevalence of incisal crowding $(23.3 \%)$ was observed in the current study against $27.3 \%$ reported in Nigeria [34]. Some minor variations in scoring malocclusions among these children might have caused the differences in prevalence between the two studies.

Regarding the distribution of malocclusions among the children 
with specific disabilities, neuropsychological, sensory and physical disabilities; children with neuropsychological disabilities had more malocclusions than the other two groups of disabilities, this result is similar to that which was reported by Oreland et al., [35] and Onyeaso [22]. Neuropsychological disabilities comprising of mental retardation, autism, Down's syndrome and Attention deficit/hyperactive disorders is the group of disabilities frequently reported to have high prevalence of malocclusions by previous studies. This may be contributed by underdevelopment of oral facial musculature $[36,37]$ and presence of oral dysfunction and parafunctions of masticatory system among some of these children [35].

Children with neuropsychological disabilities had more increased overjet of $(>5 \mathrm{~mm})$ and reverse overjet, $18.8 \%$ and $6.2 \%$ respectively, compared to children with other disabilities. While increased overjet and reverse overjet are opposing malocclusion features associated with Angle's class II and III, respectively: Their coexistence in neuropsychological group can be explained by the combination of disabilities in the group comprising of mental retardation, autism, Down's syndrome and attention deficit/hyperactive disorders.

Down's syndrome has been reported to have high class III malocclusion $[38,39]$, probably due to disharmony in cranial-base relationships $[6,13,40]$, reduced dental arch size, decreased arch length, and inadequate maxillary size [15]. Meanwhile, cerebral palsy subjects who are often mentally retarded have high prevalence of class II $[15,41]$ attributed to early eruption of primary teeth and abnormal tongue and head posture [15, 42-44]. Furthermore, lip incompetence and failure of the maxillary orbicularis muscle is another cause of excessive overjet in cerebral palsy patients [45-48].

Upper median diastema was prevalent among children with sensory disabilities than other groups of disabilities. This may either be contributed by the genes; these children may have inherited from their parents or may be due to presence of prominent buccal fraenulum.

In contrast to Muppa et al., [49], who reported the severity of anterior crowding and spacing to be higher among children with sensory disabilities, the current study revealed a higher prevalence of these types of malocclusions in children with neuropsychological disabilities and physical disabilities, again this may be contributed by poor development of oral-facial musculature with tongue and lips parafunctions common in cerebral palsy [45, 46] as well as small dental arch size especially among Down's syndrome subjects [15].

Regarding the number of anomalies (malocclusions) per individual subject, majority of children with neuropsychological disabilities had higher number of anomalies than other groups of disabilities; this might be contributed by frequency episodes of airway infection [36], frequency of oral habits and general poor muscle development $[8,35]$. The current study also found a higher prevalence of anterior open bite and deep bite among the children with neuropsychological disabilities than sensory and physical disabilities. Since the group comprises Down's syndrome, mentally retarded and cerebral palsy subjects, the open bite may be attributed to the oral habit of projecting the tongue against the teeth and frequent episodes of upper air way infection which lead to a greater prevalence of mouth breathing and malocclusions, including anterior open bite [37]. These features are common in cerebral palsy and mentally retarded patients. Meanwhile, deep bite incidence in neuropsychological disabilities may be due to Down's syndrome members of the group who are reported to have reduced vertical dimension of the maxilla and mandible, short teeth, forward rotation of maxillary and mandibular planes [50]. The present study found a low prevalence of posterior crossbite $(5.4 \%)$ than that obtained by Oliveira et al., [51] $(21.5 \%)$, among children with neuropsychological disabilities; this may also be contributed to the age differences of the studied populations. Also, different methods of scoring malocclusions may have contributed to this difference.

The study observed Class I molar relationship of about $75 \%$ among children with neuropsychological disabilities, this is in contrast to that reported by Utomi et al., [52] who found slightly lower prevalence of Class I molar relationship (68.6\%) in similar group of disabilities. Nevertheless, the observed difference in the prevalence is not so marked. Considering the space anomalies, the prevalence of crowding in incisal segment (58.8\%) reported by the current study is similar to that which was reported in Nigeria [52] in an identical group of disabilities. However, there was a considerable difference in the prevalence of spacing in incisal segment between the current and the one which was reported in Nigeria [25], this might be attributed to the difference in indices used in scoring malocclusion.

\section{Study Strength and Limitations}

The study involved children from Dar-es Salaam region, the most heterogeneous city with a mixture of tribes and socio-demographic backgrounds than any other regions in the country; this may reflect the status of occlusal conditions in such children elsewhere in Tanzania.

The study involved children with neuropsychological, physical and sensory disabilities of different levels and types. Their disabilities might have influenced the responses and cause some difficulties during clinical examination and thus affecting data collection.

\section{Conclusion}

Malocclusions were prevalent in a greater proportion of children with disabilities: In particular, neuropsychological disabled participants had significantly higher prevalence, followed by those with physical and sensory disabilities. Increased overjet, reverse overjet, open bite as well as deep bite were predominant among children with neuropsychological disabilities than other groups.

\section{Recommendations}

Malocclusions is a problem among children with neuropsychological, sensory and physical disabilities, therefore, it is very important to plan for and provide oral health care, preventive and interceptive orthodontics to children with disabilities so as to reduce a double burden to this group of children.

\section{References}

[1]. World Health Organization (1980) International Classification of Impair- 
ments, Disabilities and Handicaps; a manual of classification relating to the consequences of disease. Geneva, Switzerland.

[2]. Mitsea A, Karidis A, Donta-Bakoyianni C, Spyropoulos N (2002) Oral health status in Greek children and teenagers, with disabilities. J Clin Pediatr Dent. 26(1): 111-118.

[3]. Pezzementi ML, Fisher MA (2005) Oral health status of people with intellectual disabilities in the southeastern United States. J Am Dent Assoc. 136(7): 903-912

[4]. Bradley C, McAlister T (2004) The oral health of children with Down syndrome in Ireland. Spec Care Dentist. 24(2): 55-60.

[5]. Owens PL, Kerker BD, Zigler E, Horwitz SM (2006) Vision and oral health needs of individuals with intellectual disability. Ment Retard Dev Disabil Res Rev. 12(1): 28-40.

[6]. Brown JP, Schodel DR (1976) A review of controlled surveys of dental disease in handicapped persons. ASDC J Dent Child. 43(5): 313-320.

[7]. Abdul-Rahim FS, Mohamed AM, Nor MM, Saub R (2014) Malocclusion and orthodontic treatment need evaluated among subjects with Down syndrome using the Dental Aesthetic Index (DAI). Angle Orthod. 84(4): 600-6.

[8]. Vigild M (1985) Prevalence of malocclusion in mentally retarded young adults. Community Dent Oral Epidemiol. 13(3): 183-184.

[9]. Al-Sarheed M, Bedi R, Hunt NP (2003) Orthodontic treatment need and self-perception of 11-16-year-old Saudi Arabian children with a sensory impairment attending special schools. J Orthod. 30(1): 39-44

[10]. Grippaudo C, Pantanali F, Paolantonio EG, Grecolini ME, Saulle R, et al., (2013) Prevalence of malocclusion in Italian schoolchildren and orthodontic treatment need. Eur J Paediatr Dent. 14(4): 314-318.

[11]. Atashi M (2007) Prevalence of Malocclusion in 13-15 Year-old Adolescents in Tabriz. J Dent Res Dent Clinics Dent Prosp. 1(1): 13-18

[12]. Proffit WR, Fields HW, Moray LJ (1997) Prevalence of malocclusion and orthodontic treatment need in the United States: estimates from the NHANES III survey. Int $j$ adult orthodon orthognath surge. 13(2): 97-106.

[13]. Vittek J, Winik S, Winik A, Sioris C, Tarangelo AM, et al., (1994) Analysis of orthodontic anomalies in mentally retarded developmentally disabled (MRDD) persons. Spec Care Dentist. 14(5): 198-202.

[14]. Dinesh RB, Arnitha HM, Munshi AK (2003) Malocclusion and orthodontic treatment need of handicapped individuals in South Canara, India. Int Dent J. 53(1): 13-18.

[15]. Shyama M, al-Mutawa SA, Honkala S (2001) Malocclusions and traumatic injuries in disabled schoolchildren and adolescents in Kuwait. Spec Care Dentist. 21(3): 104-108.

[16]. Corruccini RS (1984) An epidemiologic transition in dental occlusion in world populations. Am J Orthod. 86(5): 419-426.

[17]. Waldman HB, Perlman SP, Swerdloff M (2000) Orthodontics and the population with special needs. Am J Orthod Dentofacial Orthop. 118(1): 14-17.

[18]. Kiliaridis S (1986) Masticatory muscle function and craniofacial morphology: An experimental study in the growing rat fed a soft diet. Swed Dent J Suppl. 36: 1-55.

[19]. Beecher RM, Corruccini RS (1981) Effects of dietary consistency on craniofacial and occlusal development in the rat. Angle Orthodontist. 51(1): 6169.

[20]. Yamada K, Kimmel DB (1991) The effect of dietary consistency on bone mass and turnover in the growing rat mandible. Arch Oral Biol. 36(2): 129138.

[21]. Kumin L, Bahr DC (1999) Patterns of feeding, eating, and drinking in young children with Down syndrome with oral motor concerns. Down Syndrome Quarterly. 4(2): 1-8.

[22]. Onyeaso CO (2004) Comparison of malocclusion and orthodontic treatment needs of handicapped and normal children index (DAI), Niger postgraduate Med J. 11(1): 40-44

[23]. Haliza T, Normastura AR, Azizah Y (2015) Dental anomalies and oral hygiene status of down syndrome children. IJPHCS. 2(3): 33-44.

[24]. Agrawal A, Bhatt N, Chaudhary H, Singh K, Mishra P, et al., (2013) Prevalence of anterior teeth fracture among visually impaired individuals, India. Indian J Dent Res. 24(6): 664-668.

[25]. Onyeaso CO, Aderinokun GA, Arowojolu MO (2002) The pattern of malocclusion among orthodontic patients seen in Dental Centre, University College Hospital, Ibadan, Nigeria. Afr J Med Med Sci. 31(3): 207-211.

[26]. World Health Organization (1997) Oral health surveys: basic methods. 4th (Edn), World Health Organization. Geneva.

[27]. O'Brien K, Wright JL, Conboy F, Macfarlane T, Mandall N (2006) The child perception questionnaire is valid for malocclusions in the United Kingdom. Am J Orthod Dentofacial Orthop. 129(4): 536-540.
[28]. Liu Z, McGrath C, Ha"gg U (2009) The impact of malocclusion/orthodontic treatment need on the quality of life: a systematic review. Angle Orthod. 79(3): 585-591.

[29]. Ajami BA, Shabzendedar M, Rezay YA, Asgary M (2007) Dental treatment needs of children with disabilities. J Dent Res Dent Clin Dent Prospects. 1(2): 93-98.

[30]. Altun C, Guven G, Akgun OM, Akkurt MD, Basak F, et al., (2010) Oral health status of disabled individuals attending special schools. Eur J Dent. 4(4): 361-6.

[31]. Shaw WC, Addy M, Ray C (1980) Dental and social effects of malocclusion and effectiveness of orthodontic treatment: a review Community Dentistry and Oral Epidemiology. 8(1): 36-45.

[32]. Langlois, Judith H, Cookie White Stephan (1981) Beauty and the beast: The role of physical attractiveness in the development of peer relations and social behavior. Developmental social psychology: Theory and research. 152-168.

[33]. Aggarwal P, Soni S, Dua VS (2013) Malocclusion and orthodontic treatment need in children with special needs evaluated through Dental Aesthetic Index. Indian J Dent Sci. 5(1): 600-606.

[34]. Utomi IL, Onyeaso CO (2007) Assessment of malocclusion and orthodontic treatment needs in disabled children in Nigeria. J disabil oral health. 8(1): 3-8.

[35]. Oreland A, Heijbel J, Jagell S, Persso S (1989) Oral function in the physically handicapped with or without severe mental retardation. ASDC J Dent Child. 56(1): 17-25.

[36]. Mitchell RB, Call E, Kelly J (2003) Ear, nose and throat disorders in children with Down syndrome. Laryngoscope. 113(2): 259-263.

[37]. Ortega AO, Guimarăes AS, Ciamponi AL, Marie SK (2007) Frequency of parafunctional oral habits in patients with cerebral palsy. J Oral Rehabil. 34(5): 323-328.

[38]. Shivakumar K, Chandu G, Shafiulla M (2010) Severity of Malocclusion and Orthodontic Treatment Needs among 12- to 15-Year-Old School Children of Davangere District, Karnataka, India. Eur J Dent. 4(3): 298-307.

[39]. Shivakumar KM, Chandu GN, Subba Reddy VV, Shafiulla MD (2009) Prevalence of malocclusion and orthodontic treatment needs among middle and high school children of Davangere city, India by using Dental Aesthetic Index. J Indian Soc Pedod Prev Dent. 27(4): 211-218.

[40]. Winter K, Baccaglini L, Tomar S (2008) A review of malocclusion among individuals with mental and physical disabilities. Spec Care Dentist. 28(1): $19-26$.

[41]. Ondarza A, Jara L, Bertonati MI, Blanco R (1995) Tooth malalignments in Chilean children with Down syndrome. Cleft Palate Craniofac J. 32(3): 188-193.

[42]. Desai M, Messer LB, Calache H (2001) A study of the dental treatment needs of children with disabilities in Melbourne, Australia. Aust Dent J. 46(1): 41-50.

[43]. Strodel BJ (1987) The effects of spastic cerebral palsy on occlusion. ASDC J Dent Child. 54(4): 255-260

[44]. Rodrigues dos Santos MTB, Masiero D, Novo NF, Simionato MRL (2003) Oral conditions in children with cerebral palsy. J Dent Child. 70(1): 40-46.

[45]. Forsberg CM, Tedestam G (1990) Traumatic injuries to teeth in Swedish children living in an urban area. Swed Dent J. 14(3): 115-122.

[46]. Winick M, Rosso P (1969) Head circumference and cellular growth of the brain in normal and marasmic children. J Pediatr. 74(5): 774-778.

[47]. Roche AF, Seward FS, Sunderland S (1961) Growth changes in the mongoloid head. Acta Paediatr. 50(2): 133-140.

[48]. Bhat N, Agrawal A, Nagrajappa R, Roy SS, Singh K, et al., (2011) Teeth fracture among visually impaired and sighted children of 12 and 15 years age groups of Udaipur city, India-a comparative study. Dent Traumatol. 27(5): 389-392.

[49]. Muppa R, Bhupathraja P, Duddu MK, Dandempally A, Karre DL (2013) Prevalence and determinants factors of malocclusion in population with special needs in South India. J Indian Soc Pedod Prev Dent. 31(2): 87-89.

[50]. Suri S, Tompson BD, Atenafu E (2011) Prevalence and patterns of permanent tooth agenesis in Down syndrome and their association with craniofacial morphology. Angle Orthod. 81(2): 260-9.

[51]. Oliveira AC, Paiva SM, Martins MT, Torres CS, Pordeus AI (2011) Prevalence and determinant factors of malocclusion in children with special needs. Eur J Orthod. 33(4): 413-418.

[52]. Utomi IL, Onyeaso CO (2009) Malocclusion and orthodontic treatment need of mentally handicapped children in Lagos, Nigeria. Pesqui Bras Odontopediatria Clin Integr. 9(1): 7-11. 